\title{
Soil Conservation Practices Applied by Soil Resource Development Institute (SRDI), Bandarban, Bangladesh
}

\section{Md Nayem Hasan Munna*, Nargis Akter Shapna and Sabakun Naher}

Department of Soil and Environmental Sciences, University of Barishal, Barishal, Bangladesh

*Corresponding Author: Md Nayem Hasan Munna, Department of Soil and Environmental Sciences, University of Barishal, Barishal, Bangladesh

Received: July 16, 2019; Published: August 14, 2019

DOI: 10.31080/ASAG.2019.03.0612

\section{Introduction}

Soil provides living things with food, fibers, and fuel. It supports wildlife and rural and urban activities. One of the most serious problems currently affecting agricultural productivity in developing countries of the tropics is land degradation [1]. Due to the slope and high rainfall intensity, sloping lands are faced with nutrient and water losses through runoff which may result in a reduction in soil fertility. Soil fertility is the status of soil with respect to its ability to supply adequate and balanced amount of elements essential for plant growth without a toxic concentration of any element [2]. Major increases in agricultural production have been realized in developing countries over the last half-century [3].

Last 12th February 2019, we have visited the Soil Resource Development Institute, Bandarban, Bangladesh. Another institute named Soil Conservation and Watershed Management Centre (SCWMC) is situated over there. But, the parent organization is SRDI $\left[22.177732^{\circ} \mathrm{N}, 92.188038^{\circ} \mathrm{E}\right]$ by the way. The SCWMC buildings are established on the summit (A summit is a point on a surface which is higher in elevation than all points immediately adjacent) of a hilly area. There are some other hills that are available surrounding the Soil Conservation and Watershed Management Centre. All of the hilly areas are conserved by the SCWMC. They have applied different Soil Conservation Techniques to conserve the hilly area. And, the center works as the modeling zone regarding Soil Conservation of the hilly regions. An estimated $75 \%$ of the world's poor and hungry live in rural areas and depend directly on agriculture for their livelihoods [4]. So, it is important to develop new techniques and methods of soil conservation. And, Soil resource development institute is also working on improving and adopting new methods to conserve soil.

Hills in Bangladesh occupies $12 \%$ of its geographical area of which Chittagong Hill Tracts (CHT) covers about 10\%. Approximately 1.0 million peoples of thirteen tribal groups are living on the resources of this region [5].

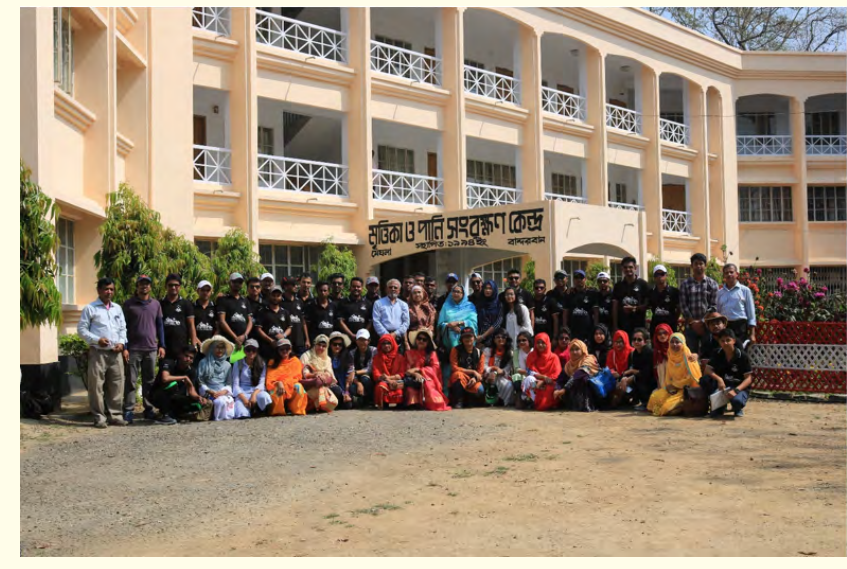

Figure 1: Soil Conservation and Watershed Management Centre [SRDI, Bandarban, Bangladesh], Photo Credit: Md. Nayem Hasan Munna.

Soil conservation practices of soil resource development institute, Bandarban, Bangladesh

Information on interrelationships between soil-conserving, runoff-reducing practices is important because in many parts of the country heterogeneity of topography or other production conditions within a single farm, together with crop diversification, make it efficient for farmers to combine several practices into an overall conservation package [6]. The innovative technologies that are applied by Soil Conservation and Watershed Management Centre (SCWMC), Meghla, Bandarban are Bench Terrace for year-round crop production, Gabion check dam for gully erosion control, Jute GeoTextile for rehabilitating degraded land, Establishment of Hedgerows in farmer's field for soil erosion control, etc.

\section{Hedgerow}

A hedgerow is a line of different kinds of bushes as well as different small trees growing very close together, especially between fields or along the sides of roads in the countryside or hilly region. 
It offers beauty, productivity, biodiversity, and much more! To control the soil erosion of the slopey hill, hedgerow technique can be applied. Contouring is applicable in this respect. The hedgerow can be applied every 4-5 m of the contour line. New technology has been invented by Soil and Water Conservation Centre, Bandarban, Bangladesh that is used to do the contour measurement in the hilly region. They used 3 pieces of bamboo to make the " $\mathrm{A}$ " shaped device and they use that to create the contour line over the slope of the hills. Along the contour line, different kind of crops such as Pineapple, Napier grass, Vetiver grass, Bogamedula, etc can be planted as the hedgerow in the fruit garden. Thus, the rate of soil erosion in the hilly region can be mitigated easily.

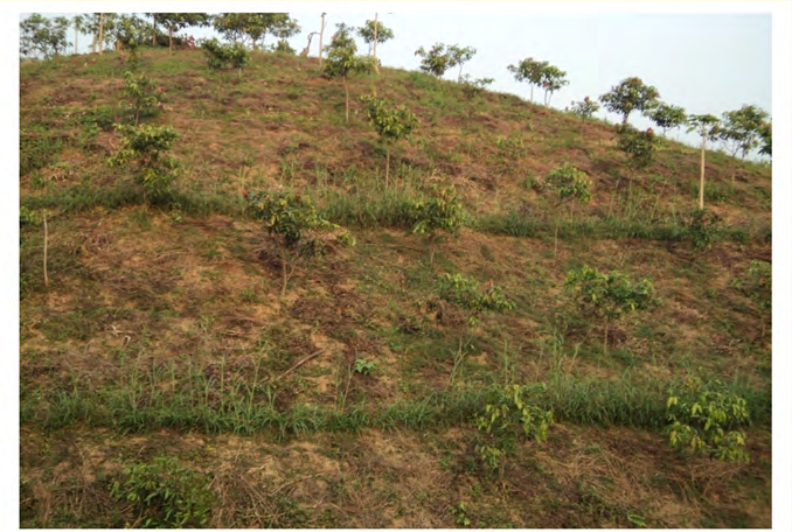

Figure 2: Hedgerows (vetiver) established in mini horticulture garden in the hill slope, Photo Credit: A. M. Zahid, SRDI.

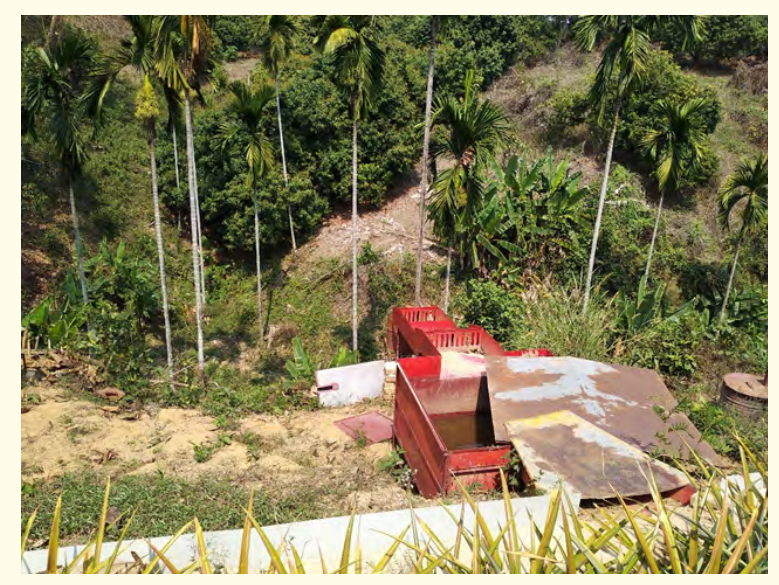

Figure 3: Multi slot divisor, Photo Credit:

Md. Nayem Hasan Munna.

\section{Advantages}

- $\quad$ Reduces soil erosion

- Improves soil fertility and soil moisture

- Provides biomass for green leaf manure
- Provides shading for young plants

- Serves as a source of fodder, fuelwood, and light construction materials

- Improves soil structure and water infiltration

- $\quad$ Provides a source of mulch [7].

\section{Limitations}

- Loss of land for cultivation due to the establishment of contour hedgerow (at least $10 \%$ of cultivated land is used)

- Hedgerows compete with food crops planted between the rows for light, soil nutrients and moisture (in the dry season). Root pruning and trimming can limit this competition.

- Hedgerow plants may be hosts to pests

- Effective retention of excess water may result in soil slippage on steep slopes. Factors affecting adoption

- Low or high temperatures may cause sterility of some hedgerow species

- It is difficult to establish contour hedgerows on very steep lands

- Most nitrogen-fixing species are not adapted to acid soils [7].

\section{Jute Geo-Textile}

Jute geotextiles can be used for control of surface soil erosion of the hilly region. This is a cost-effective technique as well. The farmers can apply the technique by spending a little amount of money. It can be applied over the slopey soil and then different live poll such as Kafal (Myrica esculenta), Semal tree (Bombax ceiba), Drumstick tree (Moringa oleifera) etc should be fixed into the soil.

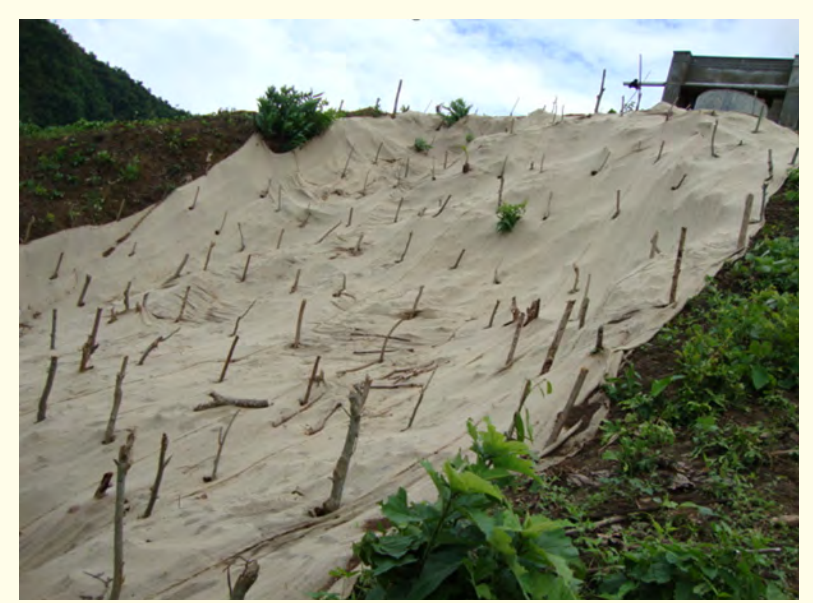

Figure 4: Reclamation of degraded sloping land by Geojute, Photo Credit: A. M. Zahid, SRDI. 
RECLAMATION OF DEGRADED SLOPING LAND BY GEOJUTE

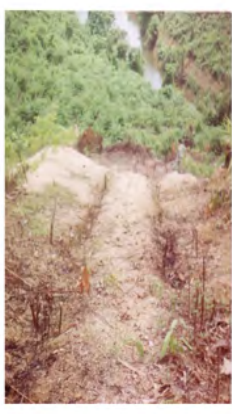

Degraded Land

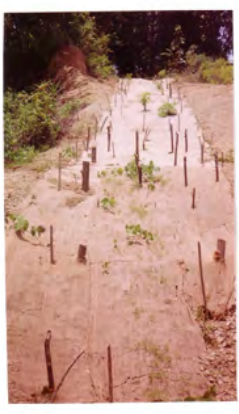

After one month

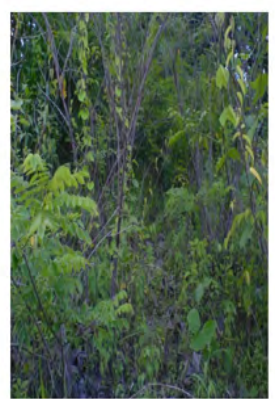

After three years
Figure 5: Reclamation of degraded sloping land by geojute (Steps), Photo Credit: A. M. Zahid, SRDI.

\section{Gabion check dam}

Gabion Check Dam can reduce velocity and may provide aeration of the water. It prevents gully erosion from occurring before vegetation is established and also cause a high proportion of the sediment load in a runoff to settle out. The technique is also costeffective. One can use the technique to control soil loss easily. But, one must be technical to set the Gabion Check Dam up in a perfect place. To control the gully erosion of the hilly soil, this kind of dam can be made. Different rocks can be used to make the dam.

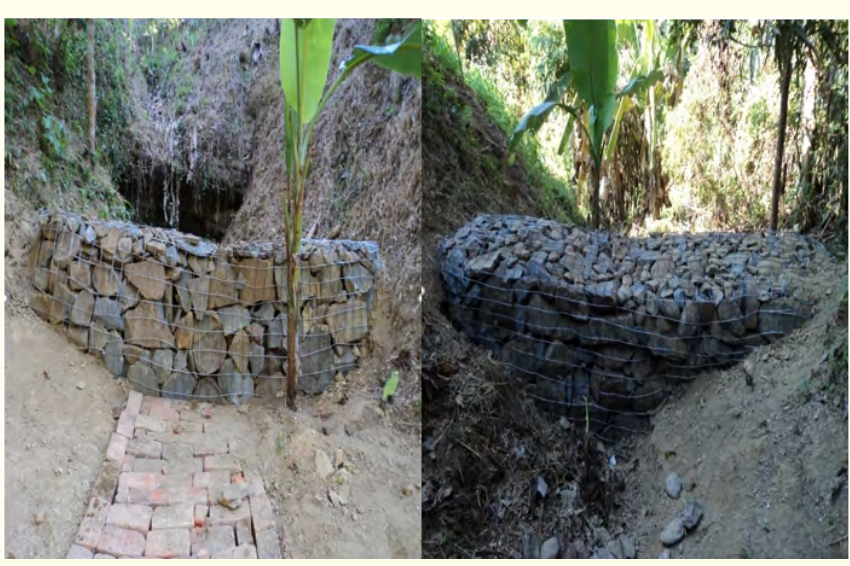

Figure 6: Gabion Check Dam (Front View at the left \& Back View at right with Apron), Photo Credit: A. M. Zahid, SRDI.

\section{Bench terrace}

Bench terraces are the series of levels or virtually level strips that run across the slope at vertical intervals, supported by steep banks or risers. The main benefit of the bench terrace is actually the conservation of soil as well as water. They reduce both the amount and velocity of water moving across the soil surface and that greatly reduces soil erosion. The technique was first applied in China and Philippine before thousand years ago to control the soil erosion of the hilly region of the countries. The method is also applied in the Soil and Water Conservation Centre in Bandarban, Bangladesh. People can cultivate their crops, apply fertilizer and the irrigation can also be done based on the bench terracing method easily.

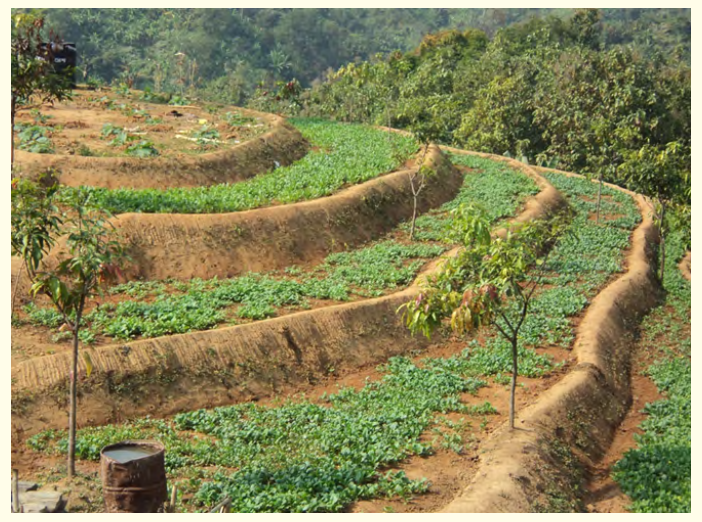

Figure 7: Bench Terrace for year-round crop production, Photo Credit: A. M. Zahid, SRDI.

A terrace is a ditch $70 \mathrm{~cm}$ deep with an earth collar which follows the contours of the land. The terraces are about thirty meters apart. The principle is the same as for the stone barriers: the terraces form an obstacle to water flow and thus limit the erosion and encourage infiltration as well. This technique is used on over a thousand hectares in the hilly reason. Digging terraces is however a huge undertaking. A single person needs a full day to dig about ten meters.

\section{Advantages}

- Controlling soil and water runoff and erosion.

- Trapping sediments in the drainage ditches built along the terrace.

- $\quad$ Reducing slope length. Every 2-3 meters of slope length is leveled to terraces. The velocity of water running down the slope is greatly reduced.

- Improving soil fertility over the long run.

\section{Half-moon terrace technique}

The method encourages the water to infiltrate into the soil to increase its fertility and limit soil erosion. When rainfall causes erosion, the upper layers of the land - the most fertile - are carried away. Preventing this phenomenon is a simple way of increasing the yield of cultivated land considerably. In addition, the technique encourages the water to infiltrate slowly into the soil and that is very beneficial in regions with insufficient rainfall. 


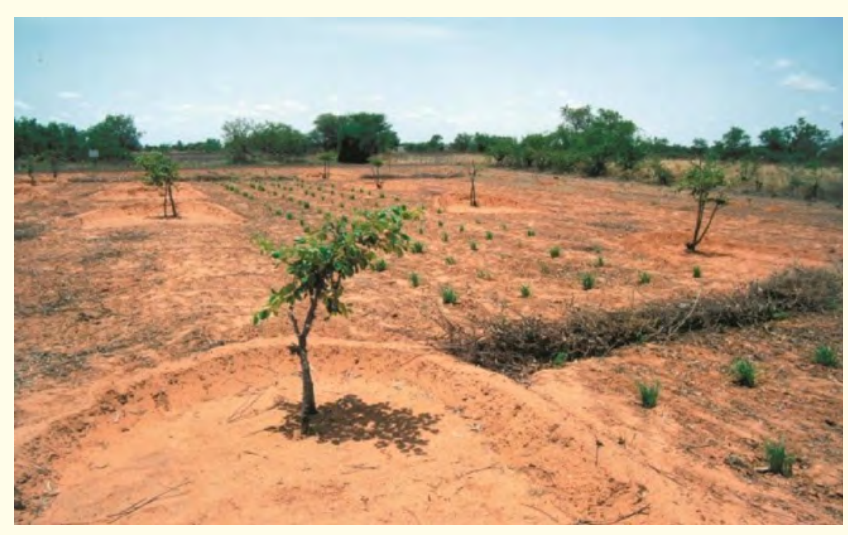

Figure 8: Half-moons technique for soil conservation.

Half-moons are semi-circular basins 2 to $6 \mathrm{~m}$ in diameter that is dug on gentle slopes $(<3 \%)$ to retain the water. Earth from cuttings is laid on the downstream edge of these basins. The downstream side of the earth collar thus created can be strengthened with pebbles. The half-moons are laid in staggered rows with four meters between them. Compost or fertilizer is spread to improve soil fertility.

Poor soils produce better results when the half-moon system is used. This method is effective for rainfall of less than $600 \mathrm{~mm}$. The effects make themselves felt in the first season. If manure is added, a production of one tonne of sorghum grain per hectare can be expected.

\section{Brushwood check dams}

The primary materials used are brushwood, posts, or pegs and the filling materials are soils and stones. This can be used on small gully heads for stabilization. Posts or pegs to be used could be sprout-producing tree species available in the area.

First, a foundation extending into the banks is dug. The brushwood is then placed between two rows of pegs driven in $40 \mathrm{~cm}$ apart across the gully bed. The distance between the rows is from 80-100 $\mathrm{cm}$ for gullies with about $5 \mathrm{~m}$ in width. The brushwood is then packed firmly and the two rows of pegs are tied together with wire. A notch or spillway of about half of the span and the top of the dam is then spared.

On the lower side of the dam; brushwood is placed lengthwise to provide an apron that will prevent scouring by overflow (Figure 3 ). It is very important that these temporary structures are supplemented by cuttings and seedlings, which will replace the brushwoods when decayed.

\section{Improved Jhum cultivation}

Bandarban hill district is of great importance for growing various crops, which are different from the plains. Farmers practice

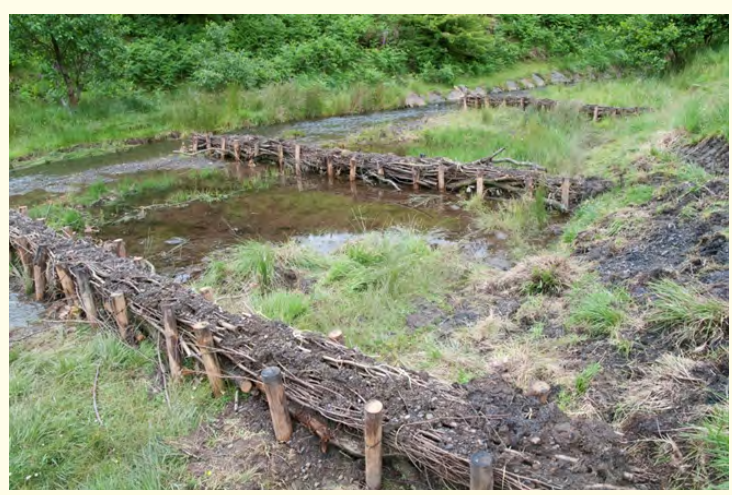

Figure 9: Brushwood check dams.

traditional Jhum culture for their livelihood [8]. Jhum cultivation (slash-and-burn agriculture) with upland rice as the major crop is the predominant land-use system in the hilly regions of the Chittagong Hill Tracts (CHT) of Bangladesh [9]. The Jhum is cultivated across the slope instead of along the slope. The farmers clean the places of seedling in the hill slopes instead of clearing the total land cover. The vegetation cleared is kept aside to add the organic matter into the soil. There is a great benefit due to the improved Jhum cultivation.

\section{Integrated watershed management}

Integrated Watershed Management Programme (IWMP) refers to the method that is implemented by the Soil Conservation and Watershed Management Centre (SCWMC), Meghla, Bandarban, Bangladesh. The main objective of IWMP is to restore ecological balance by harnessing, conserving and developing degraded natural resources such as soil, vegetative cover, and water. The USDA Water Erosion Prediction Project (WEPP) model is a process-based soil erosion prediction simulation model that has been developed by the United States Department of Agriculture (USDA) since 1985. WEPP is a continuous simulation, distributed parameter, computer program that simulates important physical processes including infiltration, runoff, soil detachment by raindrops and shallow overland flow, soil detachment by excess flow, shear stress in rills, sediment transport, and sediment deposition [10].

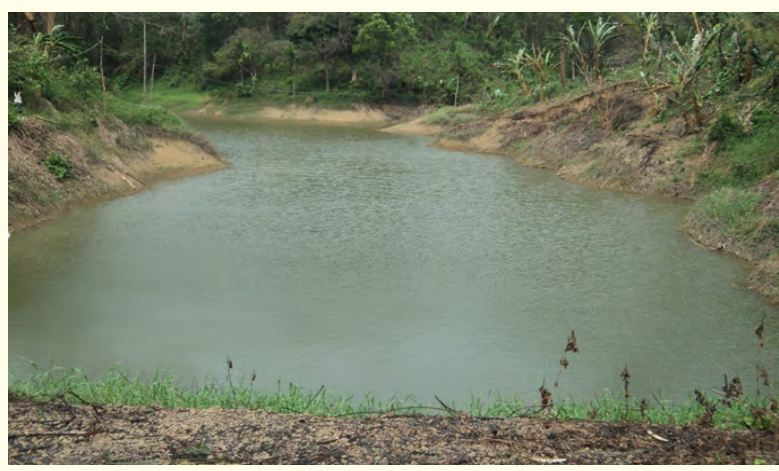

Figure 10: Integrated Watershed Management, Photo Credit: A. M. Zahid, SRDI. 


\section{Conclusion}

To sum up, there are some cost-effective and innovative techniques for soil conservation of the hilly region. The conservation practices that are visible in the Soil Conservation and Watershed Management Centre (SCWMC), Meghla, Bandarban, Bangladesh are really effective to conserve the soil from different kinds of soil degradation such as water erosion as well as nutrient depletion. The SCWMC of Bandarban, Bangladesh can be considered as the "Centre for Soil Conservation Modelling". We have to focus on the development of soil conservation techniques. The Government and different NGOs should play an important role in developing techniques by investing in different research purposes. The conservation techniques should be applied in all of the hilly regions of our country such as the Chittagong Hills in the southeast, the Low Hills of Sylhet in the northeast, and highlands in the north and northwest. Thus, we can save the soil as well as human civilization.

\section{Acknowledgment}

The authors are grateful to the Department of Soil and Environmental Sciences, University of Barishal and Soil Resource Development Institute, Bandarban, Bangladesh. They are also immensely grateful to Rtn. Jalal Uddin Shoaib, Former Chief Scientific Officer, Soil Resource Development Institute (SRDI), Bangladesh and Ameer Md. Zahid, Senior Scientific Officer, Soil Resource Development Institute (SRDI), Bangladesh. They are highly thankful to Md. Mahmudul Islam, Lecturer, Department of Soil and Environmental Sciences, University of Barishal and Kazi Md. Jahangir Kabir, Lecturer, Department of Soil and Environmental Sciences, University of Barishal.

\section{Bibliography}

1. Iheke O R. "Economics of soil conservation practices in Abia state of Nigeria". Indian Journal of Agricultural Research 46 (2012): 293-300.

2. Teh C B S., et al. "Effects of different soil conservation practices on soil fertility". (2010).

3. Ckcamo J A., et al. "On-site economic evaluation of soil conservation practices in Honduras". Agricultural Economics 11.2-3 (1994): 257-269.

4. Fungo B., et al. "Use of soil conservation practices in the Southwestern highlands of Uganda”. (2011).

5. Shoaib, J. "Socio-ecological problems in soil conservation strategy in the hilly region of Socio-Ecological Problems in Soil Conservation Strategy in Hilly Region of Bangladesh". (2016).

6. Lichtenberg, E. "Adoption Of Soil Conservation Practices: A Revealed Preference Approach Adoption of Soil Conservation Practices : A Revealed Preference Approach". (2001).
7. Mixed E., et al. "Soil Conservation measures are of four categories Agronomic Vegetative Structural Management”.

8. Hossain A and Ahmad A. "Livelihood status of hill dwellers in Bandarban, Bangladesh". Journal of Business, Managementand Social Research 3.1 (2017): 154-161.

9. Chakma S. S and Ando K. "Jhum cultivation in Khagrachari hill district of Bangladesh- a subsistence farming practices in ethnic minorities". Journal of Agroforestry and Environment 2.2 (2008): 1-8.

10. Flanagan D C and Srivastava A. "Updated Soil Conservation Practice Simulation with the WEPP Model with the WEPP Model". (2017).

Volume 3 Issue 9 September 2019 (c) All rights are reserved by Md Nayem Hasan Munna., et al. 